\title{
Assurance of Nano-Molar Amounts of a Tricyclic Antidepressant; Clomipramine Hydrochloride in Bulk, Pharmaceutics and Biological Fluids Utilizing Solid Contact Sensors
}

\author{
1,2 Sabrein H. Mohamed*, ${ }^{2}$ Yousry M. Issa, ${ }^{3}$ Shaimaa A. Elfeky \\ 1- Chemistry Department, College of Science, Jouf University, P. O. Box 2014, Sakaka, Saudi Arabia. \\ 2- Chemistry Department, Faculty of Science, Cairo University, Giza, Egypt. \\ 3- Egyptian Chemistry Administration, Cairo, Egypt. \\ *Corresponding author's E-mail: sabrein_harbi@yahoo.com
}

Received: 10-01-2021; Revised: 20-02-2021; Accepted: 26-02-2021; Published on: 20-03-2021.

\begin{abstract}
Clomipramine hydrochloride (CLPH.Cl) as a tricyclic antidepressant was analyzed utilizing newly constructed sensitive coated wire sensors. These sensors are based on the use of clomipramine-tetraphenylborate (CLPH-TPB) as the electroactive matter. A mixture of $2.0 \%$ CLPH-TPB, $49.0 \%$ polyvinyl chloride (PVC) and $49.0 \%$ tricresyl phosphate (TCP) was used. Distinctive wires and graphite pencils were checked for the closest Nernastian behavior. The sensors showed a slope of $58.71 \pm 0.27 \mathrm{mV} /$ decade over a linear concentration range of $1.0 \times 10^{-3}-10.0 \mathrm{mmol} / \mathrm{L}$ with detection limit of $0.49 \mu \mathrm{mol} / \mathrm{L}$ and correlation coefficient 0.9989 . Different additives are incorporated in the prepared mixture (Nano carbon, potassium tetraphenylborate or sodium tetraphenylborate) to enhance the sensor characteristics. The sensors exhibit stable potential within the $\mathrm{pH}$ range 2.0-7.2 and show steady state potentials within 5-10 s. Additionally, the proposed sensors were utilized for the assurance of $\mathrm{CLPH}$.Cl in pure form, pharmaceutics (Anafronil ${ }^{\circ}$ tablets) and biological fluids (spiked human serum and urine) reaching a limit of detection of $30.0 \mathrm{nmol} / \mathrm{L}$ on the basis of standard addition method. The obtained recovery values lay in the range $98.28-103.66 \%$. The results were statistically compared with the British pharmacopeial method, demonstrating no critical distinction with respect to its accuracy and precision.
\end{abstract}

Keywords: Clomipramine hydrochloride, Polyvinyl chloride, solid contact sensor, Nano carbon.

QUICK RESPONSE CODE $\rightarrow$

DOI:

10.47583/ijpsrr.2021.v67i01.007

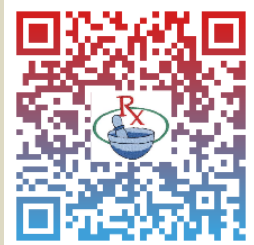

DOI link: http://dx.doi.org/10.47583/ijpsrr.2021.v67i01.007

\section{INTRODUCTION}

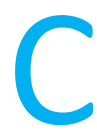

lomipramine hydrochloride (CLPH.Cl) belongs to tricyclic antidepressants which are broadly used to treat real depressive disorder and significant anxiety disorder ${ }^{1}$ by inhibiting the reuptake of serotonin and hindering its transporters ${ }^{2}$. Its name is 3-(3-chloro-10,11dihydro-5H-dibenzo[b,f]azepin-5-yl)-N,N-dimethylpropan1-amine hydrochloride. Its molar mass is $351.3 \mathrm{~g} \mathrm{~mol}^{-1}$. Different systematic techniques have been reported for the quantification of CLPH.Cl including spectral analyses, ${ }^{3-}$ ${ }^{8}$ chromatography. ${ }^{9-16}$ The majority of these strategies are tedious techniques and in light of utilizing of refined instrument. Consequently, suggesting an electrochemical strategy utilizing an ion-selective sensor is a decent applying elective technique for the medication investigation. Ion-selective sensors are assuming an imperative investigation due to its simplicity, rapidity and accuracy over some other analytical technique. ${ }^{17-21}$ Some previously published ion selective sensors were constructed for the quantification of CLPH.Cl in the pure and pharmaceutical formulations utilizing membrane and chemically modified carbon paste sensors ${ }^{23-26}$ and they were summarized in our previously published work. ${ }^{23}$

The present work expects to create coated solid contact sensors for the assurance of CLPH.Cl in the pure, pharmaceutical and biological samples where there is no previously published sensor for its analysis from this type. Besides, it studies the performance characteristics and the applicability in the analysis of pure solutions, pharmaceutics, spiked human serum and urine samples utilizing potentiometric titration and standard addition methods. The proposed CLPH-sensors were produced on the view of fuse of CLPH-TPB, scheme 1 , as the electroactive matter in a plasticized PVC to get ready layer and covered wire sensors. They were characterized and upgraded according to IUPAC suggestions. ${ }^{22}$

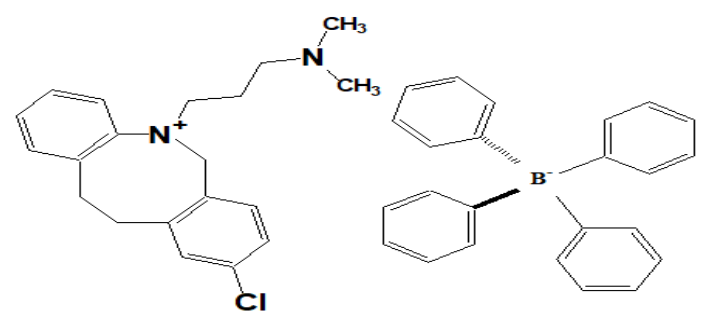

Scheme 1: Chemical structure of clomipramine hydrochloride -tetra phenyl borate ion pair

Graphite is considered as the astounding level of coal, which has been used in the development of sensors because of its thermal and electrical conductivity. The 
hardness of graphite pencils contrasts relying upon its quality and where the pencil was made. Delicate lead was labeled "B" for black and "H" for hard. "F" is a letter chosen to indicate midway between $\mathrm{HB}$ and $\mathrm{H}$. An $\mathrm{HB}$ pencil is in the half way amongst hard and delicate. Scheme 2 shows the distinctive grades of graphite pencils.

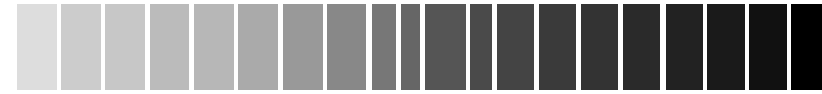
$\begin{array}{llllllllllllllllllll}9 & 8 & 7 & 6 & 5 & 4 & 3 & 2 \\ \mathrm{H} & \mathrm{H} & \mathrm{H} & \mathrm{H} & \mathrm{H} & \mathrm{H} & \mathrm{H} & \mathrm{H} & \mathrm{H} & \mathrm{F} & \mathrm{H} & \mathrm{B} & 2 & 3 & 4 & 5 & 6 & 7 & 8 & 9 \\ \mathrm{~B} & \mathrm{~B} & \mathrm{~B} & \mathrm{~B} & \mathrm{~B} & \mathrm{~B} & \mathrm{~B} & \mathrm{~B}\end{array}$
Hardest $\rightarrow \quad$ Medium $\rightarrow \quad$ Softest

Scheme 2: Diverse grades of graphite pencils in plummeting request as per their hardness.

\section{MATERIALS AND METHODS}

\section{Reagents and Materials}

Clompramine $\mathrm{HCl}$ and its pharmaceutics (Anafronil ${ }^{\circ}$ tablets, 25 and $50 \mathrm{mg} /$ tablet) were obtained from NOVARTIS PHARMA S.A.E. Cairo, Egypt. Dibutyl phthalate (DBP), ethylhexyladipate (EHA), dioctyl phthalate (DOP), dioctylsebacate (DOS) o-nitrophenyl phenyl ether (ONPPE), tricresyl phosphate (TCP), o-nitrophenyloctyl ether (ONPOE) and sodium tetraphenylborate (NaTPB), were gotten from SigmaAldrich, USA. All chemicals and reagents were of analytical grade. Doubly distilled water was utilized through all the work. $^{23}$

\section{Solutions}

The working standard solutions were set up by appropriate dilution of the stock $10.0 \mathrm{mmol} / \mathrm{L} \mathrm{CLPH.Cl}$ solution. The later was set up by dissolving, $35.13 \mathrm{mg}$ in $100 \mathrm{~mL}$ doubly distilled water. A $10.0 \mathrm{mmol} / \mathrm{L}$ NaTPB standard solution was prepared by dissolving $34.22 \mathrm{mg}$ into $100 \mathrm{~mL}$ doubly distilled water. Solutions of sodium hydroxide and hydrochloric acid of concentrations within the range 0.1 -
$1.0 \mathrm{~mol} / \mathrm{L}$ were utilized for altering the $\mathrm{pH}$ of the medium. The stock solutions and the diluted ones were kept in dark brown bottles in the fridge.

To explore the selectivity of the proposed sensors, 0.1 $\mathrm{mol} / \mathrm{L}$ lactose, sucrose, DL-asparagine, L-threonine, Dalanine, DL-histidine, L-cysteine, and DL-serine (gotten from Aldrich Chemical Company), chloride solutions of $\mathrm{Na}^{+}, \mathrm{Ca}^{2+}, \mathrm{Cu}^{2+}, \mathrm{K}^{+}, \mathrm{NH}_{4}{ }^{+}$and $\mathrm{Mg}^{2+}$ and nitrate solution of $\mathrm{Fe}^{3+}$, (gotten from Adwic Chemical Company, Abu-Zabal, Egypt), were prepared. ${ }^{23}$

\section{Preparation of Clomipramine-Tetraphenylborate (CLPH- TPB)}

It was prepared as described in our previously work ${ }^{23}$ by blinding $50 \mathrm{~mL} 10.0 \mathrm{mmol} / \mathrm{L} \mathrm{CLPH.Cl}$ with $50 \mathrm{~mL} 10.0$ $\mathrm{mmol} / \mathrm{L} \mathrm{NaTPB}$, under stirring.

\section{Preparation of Sensor Coating Mixture}

The blend was prepared by dissolving diverse amounts of CLPH-TPB covering the range of 1.0-5.0\%, distinct amounts of PVC and different types of plasticizers in $5 \mathrm{~mL}$ tetrahydrofuran (THF). The aggregate weight of constituent in each cluster is settled at $200 \mathrm{mg}$.

\section{Preparation of Coated Wire Sensors}

Unadulterated silver ( $2 \mathrm{~mm}$ diameter and $6 \mathrm{~cm}$ length), copper (3 $\mathrm{mm}$ diameter and $6 \mathrm{~cm}$ length), glassy carbon (GC) (5 mm diameter and $6 \mathrm{~cm}$ length) and pencil graphite rods ( $2 \mathrm{~mm}$ diameter and $6 \mathrm{~cm}$ length) of diverse grades were tightly insulated using poly ethylene tubes leaving 2 $\mathrm{cm}$ at one end for coating and $1 \mathrm{~cm}$ at the other end for connection. The rod surface of each type was coated with the active membrane by ducking the uncovered end into the coating solution and allowing the film to dry in air for about $5 \mathrm{~min}$. The process was done until a plastic film of around $1.0 \mathrm{~mm}$ thickness was formed (around 10 times). The prepared sensors were preconditioned by soaking in $1.0 \mathrm{mmol} / \mathrm{L}$ solution of CLPH.Cl for various time interims.
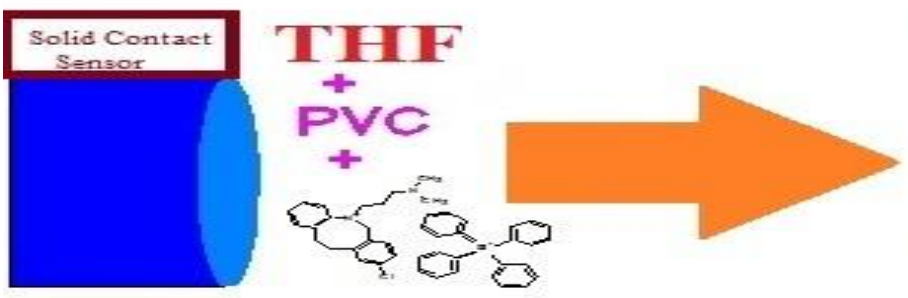

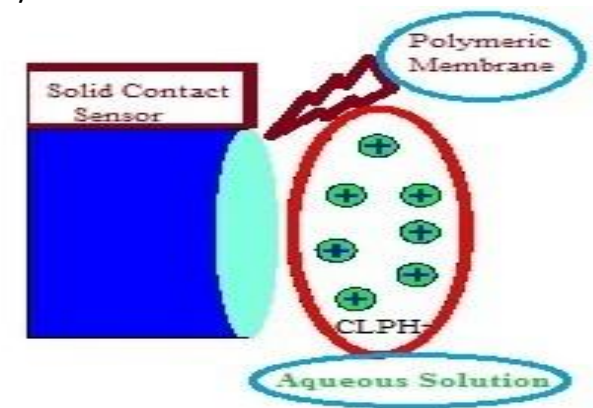

Scheme 2: Schematic representation for the preparation of solid contact sensors

\section{Instrumentation}

The potentiometric and $\mathrm{pH}$ estimations were done with a Jenway 3010 digital $\mathrm{pH} / \mathrm{mV}$ meter. A saturated calomel electrode (SCE) was used as the external reference. The electrochemical arrangement of the sensors would be represented as sensor/test solution|SCE. The temperature was adjusted utilizing Thermostat, Model C-100 (Cambridge, England).

\section{Effect of $\mathrm{pH}$}

The effect of $\mathrm{pH}$ on the response of the prepared sensors was tested using $0.1,0.5$ and $1.0 \mathrm{mmol} / \mathrm{L} \mathrm{CLPH.Cl}$. The $\mathrm{pH}$ of the solution was covered the range $1.0-12.0$ by adding small amounts of $1.0 \mathrm{~mol} / \mathrm{L} \mathrm{HCl}$ or $\mathrm{NaOH}$ solutions. The emf readings were drawn against the $\mathrm{pH}$ for the diverse drug concentrations. 


\section{Effect of Temperature}

Calibration graphs were constructed at different test solution temperatures $(\mathrm{t})(25-55 \mathrm{o})$ to look for the thermal coefficient of the suggested sensors. The standard sensor potential values $\left(\mathrm{E}^{\mathrm{o}}\right.$ sen $)$ at each temperature were calculated in this temperature range. The values of $\mathrm{E}$ o were plotted versus (t-25). The slope of those straight lines presents the thermal coefficient (dEo/dt) which was computed for each sensor using equation (1):

$\mathrm{E} \underline{\mathrm{cell}}_{\text {cll }}=\mathrm{E} \mathrm{o}_{25 \mathrm{o}} \mathrm{C}+(\mathrm{dE} \mathrm{o} / \mathrm{dt})(\mathrm{t}-25)$

Plot of $\mathrm{E}_{\text {cell }}$ versus ( $\left.\mathrm{t}-25\right)$ produced a straight line whose slope is taken as the thermal coefficient of the cell. The values of the standard potentials of the sensors ( $\mathrm{E}_{\text {sen }}$ ) were calculated after subtraction of the potential of the SCE at different temperatures. ${ }^{27}$

\section{Response to other lons}

The selectivity coefficient values $\left(\mathrm{K}_{\mathrm{CLPH}^{+}, \mathrm{j}^{\mathrm{z}+}}^{\text {pot }}\right)$ were resolved by IUPAC suggestions utilizing the matched potential strategy. ${ }^{26}$ It is known as the ratio of essential and interferent which obtain the similar potential change under comparable conditions. $\mathrm{K}_{\mathrm{CLPH}^{+},{ }^{\mathrm{z}}{ }^{\mathrm{z}}}$ was determined by applying equation (2): ${ }^{28}$

$\mathrm{K}_{\mathrm{CLPH}^{+}, \mathrm{j}^{\mathrm{z}}}^{\mathrm{pot}}=\left(\mathrm{a}_{\mathrm{CLPH}}\right) /\left(\mathrm{a}_{\mathrm{j}}\right)$

Where acLPH and $a_{\mathrm{j}}$ : the activity of the drug and the added interferent, respectively.

\section{Analytical Applications}

CLPH.Cl was analyzed in the pure form, pharmaceutical preparation (Anafronil tablets) and spiked human serum and urine samples applying the standard addition and potentiometric titration methods. The standard addition method was carried out by adding small volumes of pure $\mathrm{CLPH} . \mathrm{Cl}$ solution to an aliquot of samples of diverse concentrations covering the range from 0.1 to $1.0 \times 10^{4}$ $\mu \mathrm{mol} / \mathrm{L}$. The potential reading was observed for each and every increment and used to report the concentration in the tested solution utilizing equation (3). ${ }^{29}$

$C_{x}=C_{s}\left(\frac{V s}{V x+V s}\right)\left(10^{n(\Delta E / S)}-\frac{V x}{V s+V x}\right)^{-1}$

Where:

$\mathrm{Cx}, \mathrm{Cs}, \mathrm{Vx}$, and Vs: are the concentrations to be resolved, the concentration of standard CLPH.Cl included, the starting volume and the volume included of standard CLPH.Cl, respectively.

$\mathrm{S}$ : is the slope of the alignment bend

$\Delta \mathrm{E}:$ is the potential change after expansion.

Making utilization of the potentiometric titration, distinctive volumes from $10.0 \mathrm{mmol} / \mathrm{L} \mathrm{CLPH.Cl}$ were weakened to $50 \mathrm{~mL}$ utilizing doubly distilled water and the subsequent arrangements were titrated against 1.0 or 10.0 $\mathrm{mmol} / \mathrm{L}$ NaTPB. The emf esteems were processed and plotted against the volume of NaTPB (V). The end focuses were distinguished from the customary S-formed plots and the first derivative.

\section{Investigation of Tablets}

Ten Anafronil ${ }^{\oplus}$ tablets were precisely weighed and ground to fine powder in an agate mortar and a known weight was taken from this powder and blended with $30 \mathrm{~mL}$ of doubly distilled water at that point, the later was separated in 50 $\mathrm{mL}$ estimating flask. The remained powder was washed three times with a similar dissolvable and the volume was finished to the check. Following that, the standard addition and potentiometric titration techniques were connected.

\section{Investigation of Serum and Urine Samples}

Intended for serum investigation, about $4 \mathrm{~mL}$ of blood was centrifuged for $10 \mathrm{~min}$ at $1500 \mathrm{rpm}$, and then one $\mathrm{mL}$ serum was transferred to a $50 \mathrm{~mL}$ estimating flask. For urine investigation, one $\mathrm{mL}$ aliquot of it was moved into 50 $\mathrm{mL}$ estimating flask. Diverse volumes of $10.0 \mathrm{mmol} / \mathrm{L}$ $\mathrm{CLPH} . \mathrm{Cl}$ solution were included so the last fixation was at the scope of $0.1-100.0 \mu \mathrm{mol} / \mathrm{L}$. The later were mixed well and completed to volume level with doubly distilled water. The later were blended well and finished to volume level with doubly distilled water. These arrangements were dissected as depicted above utilizing the standard addition strategy.

\section{RESULTS AND DISCUSSION}

\section{Performance Characteristics of the Sensors}

To choose the best composition of the readied covering blend, CLPH-TPB (1-5\%) were utilized to acquire the ideal creations and tried as a membrane sensor. The later was set up by pouring the mixture into a Petri dish $(5 \mathrm{~cm}$ in measurement), secured with a filter paper and the dissolvable was permitted to dissipate gradually at room temperature. For every circumstance, consequent to curing little circles $(7.5 \mathrm{~mm}$ in estimation) were punched from the thrown films and mounted in a natively constructed sensor boat. The sensor was filled with 10.0 $\mathrm{mmol} / \mathrm{L} \mathrm{KCl}$ and $1.0 \mathrm{mmol} / \mathrm{L} \mathrm{CLPH.Cl}$ then it was preconditioned in $1.0 \mathrm{mmol} / \mathrm{L} \mathrm{CLPH.Cl}$ solution.

The best outcome was gotten from mixing $2 \%$ CLPH-TPB, Table 1. The impact of various plasticizers on the performance qualities of the sensor, with creation of $2 \%$ CLPH-TPB, was contemplated, Table 2. The information demonstrates that the utilization of TCP as a plasticizer gave the best outcomes with the closest Nernstian slope $\left(56.28 \pm 0.08 \mathrm{mV} /\right.$ decade) over a wide range $\left(5.96 \times 10^{-3}\right.$ $10.0 \mathrm{mmol} / \mathrm{L})$ with LOD and LOQ 5.38 and $10.79 \mu \mathrm{mol} / \mathrm{L}$, individually. Where on account of different plasticizers, the slope of the adjustment charts is entirely different from the normal Nernstian esteem; $59.5 \mathrm{mV} /$ decade. Diverse wires were then tried utilizing the achieved composition; 2.0\% CLPH-TPB, 49.0\% PVC and 49.0\% TCP. The slopes, concentration ranges and detection limits of solid contact sensors are affected by the idea of the bed. Ag and Cu, GC and graphite pencils (GHB) are utilized for this reason. 


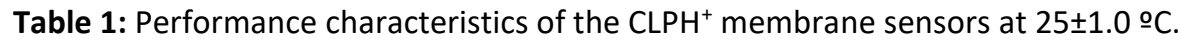

\begin{tabular}{|c|c|c|c|c|c|c|c|}
\hline \multicolumn{3}{|c|}{ Composition(w/w\%) } & \multirow{2}{*}{$\begin{array}{l}\text { Slope } \pm \text { SE } \\
\mathrm{mV} / \text { decade }\end{array}$} & \multirow{2}{*}{$\begin{array}{c}\text { Linear range } \\
\mathrm{mmol} / \mathrm{L}\end{array}$} & \multirow{2}{*}{$\begin{array}{c}\text { LOD } \\
\mu \mathrm{mol} / \mathrm{L}\end{array}$} & \multirow{2}{*}{$\begin{array}{c}\text { RSD* } \\
\%\end{array}$} & \multirow[t]{2}{*}{$r^{2}$} \\
\hline I.P & Plast. & PVC & & & & & \\
\hline 1 & 49.5 DBP & 49.5 & $50.20 \pm 0.37$ & $9.90 \times 10^{-3}-10.0$ & 9.32 & 1.30 & 0.9987 \\
\hline $2^{\mathrm{a}}$ & 49.0 DBP & 49.0 & $52.43 \pm 0.28$ & $9.90 \times 10^{-3}-10.0$ & 6.17 & 0.95 & 0.9997 \\
\hline 3 & 48.5 DBP & 48.5 & $51.72 \pm 0.31$ & $1.96 \times 10^{-2}-10.0$ & 147.00 & 1.06 & 0.9992 \\
\hline 5 & 47.5 DBP & 47.5 & $50.62 \pm 0.27$ & $2.53 \times 10^{-2}-10.0$ & 1.67 & 0.95 & 0.9986 \\
\hline 2 & $49.0 \mathrm{DOS}$ & 49.0 & $55.92 \pm 0.15$ & $1.17 \times 10^{-2}-10.0$ & 8.88 & 0.48 & 0.9983 \\
\hline $2^{b}$ & 49.0 TCP & 49.0 & $56.28 \pm 0.08$ & $5.96 \times 10^{-3}-10.0$ & 5.38 & 0.24 & 0.9998 \\
\hline 2 & 49.0 oNPOE & 49.0 & $51.63 \pm 0.14$ & $1.96 \times 10^{-2}-10.0$ & 1.76 & 0.54 & 0.9994 \\
\hline 2 & $49.0 \mathrm{DOP}$ & 49.0 & $53.45 \pm 0.35$ & $7.93 \times 10^{-3}-10.0$ & 8.10 & 1.15 & 0.9990 \\
\hline 2 & 49.0 EHA & 49.0 & $52.66 \pm 0.35$ & $9.90 \times 10^{-2}-10.0$ & 140.00 & 1.15 & 0.9996 \\
\hline
\end{tabular}

The impact of three sorts of added substances like Nano carbon (NC), potassium tetraphenylborate (KTPB) and NaTPB on the reaction qualities of solid contact sensors was considered. Consolidation of added substances genuinely influences the performance attributes of CLPHTPB solid contact sensors particularly GHB sensor. Table 2 and Fig 1 demonstrated that, for GC based sensor, the LOD diminished fundamentally however the slope value is steady or diminished. For GHB based sensor, on including $0.5 \% \mathrm{KTPB}$, the slope value enhanced from $52.09 \pm 0.21$ to $58.71 \pm 0.27 \mathrm{mV} /$ decade, the LOD reduced to $0.49 \mu \mathrm{mol} / \mathrm{L}$, and the range is $1.0 \times 10^{-3}-10.0 \mathrm{mmol} / \mathrm{L}$. Then again, if there should arise an occurrence of different added substances slopes, ranges and LODs stay consistent or don't change altogether. The impact is unbeneficial if there should arise an occurrence of $\mathrm{Ag}$ and $\mathrm{Cu}$ CWSs in light of the fact that the slope value diminished, the range and the LOD stay consistent or don't change fundamentally. Clearly the GHB rod with incorporation of $2.0 \% \mathrm{CLPH}-\mathrm{TPB}+0.5 \%$ KTPB+48.75\% PVC+48.75\% TCP (GHB/KTPB) is the best solid contact sensor utilized all through this examination.

Table 2: Effect of different additives percentage on the performance characteristics of CLPH-TPB solid contact sensors.

\begin{tabular}{|c|c|c|c|c|c|}
\hline Additive & Slope $\pm S . E$ & Linear range & LOD & RSD & $r^{2}$ \\
\hline$\%$ & $\mathrm{mV} /$ decade & $\mathrm{mmol} / \mathrm{L}$ & $\mu \mathrm{mol} / \mathrm{L}$ & $\%$ & \\
\hline \multicolumn{6}{|c|}{ GC } \\
\hline ---- & $56.97 \pm 0.20$ & $5.96 \times 10^{-3}-10.0$ & 2.34 & 0.71 & 0.9988 \\
\hline $0.5 \mathrm{NC}$ & $54.25 \pm 0.31$ & $3.90 \times 10^{-3}-10.0$ & 1.42 & 1.15 & 0.9953 \\
\hline $1.0 \mathrm{NC}$ & $52.70 \pm 0.18$ & $3.98 \times 10^{-3}-10.0$ & 1.08 & 0.69 & 0.9968 \\
\hline 0.5 KTPB & $56.63 \pm 0.23$ & $7.50 \times 10^{-4}-10.0$ & 0.36 & 0.83 & 0.9990 \\
\hline 1.0 KTPB & $55.84 \pm 0.16$ & $1.19 \times 10^{-3}-10.0$ & 0.75 & 0.61 & 0.9993 \\
\hline $0.5 \mathrm{NaTPB}$ & $56.24 \pm 0.06$ & $7.99 \times 10^{-4}-10.0$ & 0.61 & 0.24 & 0.9979 \\
\hline 1.0 NaTPB & $52.74 \pm 0.14$ & $3.99 \times 10^{-4}-10.0$ & 0.27 & 0.57 & 0.9987 \\
\hline \multicolumn{2}{|c|}{ GHB } & & & & \\
\hline ---- & $52.38 \pm 0.22$ & $5.96 \times 10^{-3}-10.0$ & 1.85 & 0.87 & 0.9987 \\
\hline $0.5 \mathrm{NC}$ & $52.59 \pm 0.26$ & $3.98 \times 10^{-3}-10.0$ & 1.27 & 1.01 & 0.9936 \\
\hline $1.0 \mathrm{NC}$ & $52.09 \pm 0.21$ & $1.99 \times 10^{-3}-10.0$ & 0.97 & 0.82 & 0.9959 \\
\hline$* 0.5$ KTPB & $58.71 \pm 0.27$ & $1.00 \times 10^{-3}-10.0$ & 0.49 & 0.92 & 0.9989 \\
\hline 1.0 KTPB & $53.66 \pm 0.22$ & $1.99 \times 10^{-3}-10.0$ & 0.84 & 0.85 & 0.9971 \\
\hline $0.5 \mathrm{NaTPB}$ & $52.84 \pm 0.23$ & $1.19 \times 10^{-3}-10.0$ & 0.94 & 0.86 & 0.9956 \\
\hline $1.0 \mathrm{NaTPB}$ & $52.67 \pm 0.20$ & $3.99 \times 10^{-4}-1.0$ & 0.25 & 0.77 & 0.9976 \\
\hline \multicolumn{6}{|c|}{$\mathrm{Ag}$} \\
\hline ---- & $52.48 \pm 0.28$ & $3.98 \times 10^{-3}-10.0$ & 2.55 & 1.07 & 0.9982 \\
\hline $0.5 \mathrm{NC}$ & $48.56 \pm 0.44$ & $5.96 \times 10^{-3}-10.0$ & 3.17 & 1.83 & 0.9947 \\
\hline
\end{tabular}




\begin{tabular}{|c|c|c|c|c|c|}
\hline $1.0 \mathrm{NC}$ & $44.00 \pm .0 .31$ & $1.19 \times 10^{-3}-10.0$ & 0.84 & 1.42 & 0.9980 \\
\hline $0.5 \mathrm{KTPB}$ & $40.84 \pm 0.49$ & $3.98 \times 10^{-3}-10.0$ & 1.15 & 2.40 & 0.9959 \\
\hline $1.0 \mathrm{KTPB}$ & $48.66 \pm 0.37$ & $5.96 \times 10^{-3}-10.0$ & 3.98 & 1.52 & 0.9972 \\
\hline $0.5 \mathrm{NaTPB}$ & $46.62 \pm 0.13$ & $1.19 \times 10^{-3}-10.0$ & 0.94 & 0.60 & 0.9925 \\
\hline $1.0 \mathrm{NaTPB}$ & $44.87 \pm 0.24$ & $3.98 \times 10^{-3}-10.0$ & 2.19 & 1.08 & 0.9959 \\
\hline & & $\mathrm{Cu}$ & & & \\
\hline--- & $52.72 \pm 0.27$ & $7.93 \times 10^{-3}-10.0$ & 4.03 & 1.05 & 0.9966 \\
\hline $0.5 \mathrm{NC}$ & $49.61 \pm 0.18$ & $1.99 \times 10^{-3}-10.0$ & 1.00 & 0.75 & 0.9979 \\
\hline $1.0 \mathrm{NC}$ & $51.60 \pm 0.32$ & $3.98 \times 10^{-3}-10.0$ & 2.47 & 1.28 & 0.9959 \\
\hline $0.5 \mathrm{KTPB}$ & $52.61 \pm 0.34$ & $3.98 \times 10^{-3}-10.0$ & 3.01 & 1.31 & 0.9961 \\
\hline $1.0 \mathrm{KTPB}$ & $48.28 \pm 0.43$ & $3.98 \times 10^{-3}-10.0$ & 1.88 & 1.78 & 0.9972 \\
\hline $0.5 \mathrm{NaTPB}$ & $51.96 \pm 0.88$ & $5.96 \times 10^{-3}-10.0$ & 3.85 & 1.09 & 0.9965 \\
\hline $1.0 \mathrm{NaTPB}$ & $50.90 \pm 0.19$ & $3.98 \times 10^{-3}-10.0$ & 1.87 & 0.75 & 0.9961 \\
\hline
\end{tabular}

SE: standard error, ${ }^{*} \mathrm{RSD} \%$ of four replicate measurements, $r^{2}$ : correlation coefficient, NC: nano carbon, GC: glassy carbon, GHB: graphite of type HB

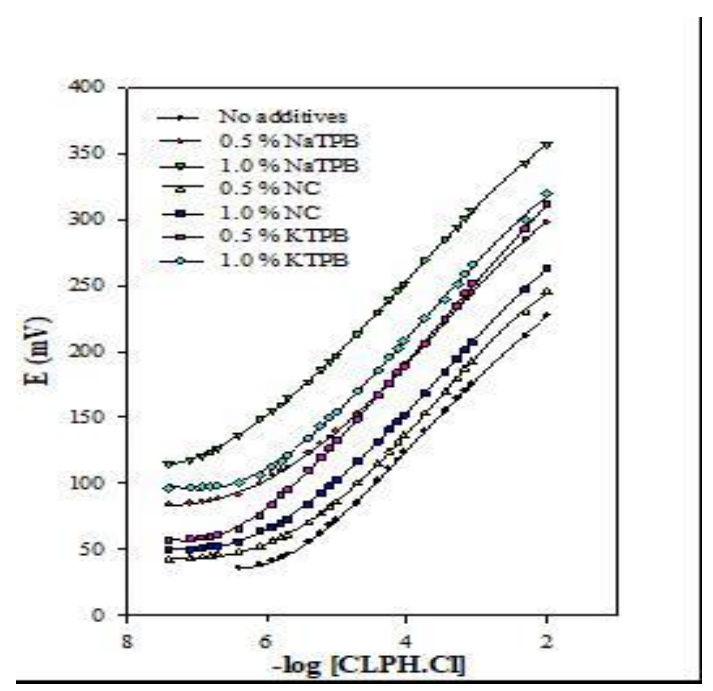

Figure 1: Effect of different percentages of additives on the CLPH-TPB GHB sensor.

The impact of splashing on the performance of the solid contact sensors was additionally examined by immersing every sensor in $1.0 \mathrm{mmol} / \mathrm{L} \mathrm{CLPH.Cl}$ for variable time interims. The outcomes demonstrated that the life expectancies $(t)$ of them, all in all, are equivalent or not exactly those of the comparative membrane one. This might be credited to the poor mechanical bond of the PVCbased touchy layer to the conductive bed surface and inadequate electrochemical solidness. It was discovered that the life expectancies of GC, GHB, GHB/KTPB, Cu and $\mathrm{Ag}$ are 15 days (slope $=56.87 \mathrm{mV} /$ decade), 15 days (slope = $54.45 \mathrm{mV} /$ decade), 30 days (slope $=50.54 \mathrm{mV} /$ decade), 4 days (slope $=51.41 \mathrm{mV} /$ decade) and $1 \mathrm{~h}$ (slope $=51.64$ $\mathrm{mV} /$ decade), individually. GHB/KTPB was observed to be the best solid contact sensor which has somewhat long life time. After this period there is a sudden decline in the slope and the detection limit increases which might be ascribed to the leaching of plasticizer and CLPH-TPB from the polymeric layer into the solution ${ }^{30}$.

\section{Effect of $\mathrm{pH}$}

The impact of $\mathrm{pH}$ on the sensor reaction was checked utilizing three distinct concentrations of CLPH.Cl (0.1, 0.5 and $1.0 \mathrm{mmol} / \mathrm{L}$ ) by estimating the variety in emf esteems with change in $\mathrm{pH}$ by adding little volumes of hydrochloric acid and sodium hydroxide (each 0.1-1.0 mol/L). The outcomes demonstrate that, the sensors demonstrate no potential change with respect to the $\mathrm{pH}$ change in the scope of 2.0-7.5, Fig. 2. At higher $\mathrm{pH}$ esteems the potential reductions bit by bit and this can presumably be credited to the formation of the free base in the solution prompting the decline in its concentration ${ }^{31}$.

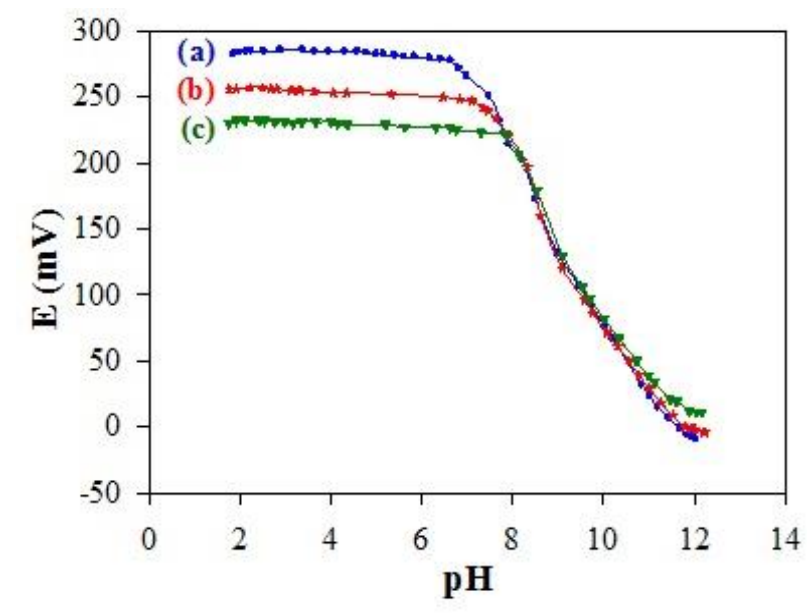

Figure 2: Effect of $\mathrm{pH}$ on the potential response of GHB/KTPB sensors, in (a) 1.0, (b) 0.5 and (c) $0.1 \mathrm{mmol} / \mathrm{L}$ $\mathrm{CLPH} . \mathrm{Cl}$ solutions.

The response time is a critical parameter for any sensor ${ }^{22}$, in which the time required to accomplish an unfaltering state potential (within $\pm 1 \mathrm{mV}$ ) was estimated after progressive submersion of the sensor in a progression of CLPH.Cl solution each having a 10 -crease increment in focus from $1.0 \times 10^{-2}$ to $10.0 \mathrm{mmol} / \mathrm{L}$. The sensor demonstrated stady state possibilities within 5-10 s. 


\section{Effect of Temperature}

The test solution impacts the capacity of the sensor as showed by the Nernst condition. To examine the thermal stability of sensors, calibration diagrams were developed at various test arrangement temperatures $(t)$ covering the scope of 25-55 ㅇ․ The outcomes demonstrate that the slopes of the alignment diagrams still in the Nernstian run over the contemplated temperature run.

To decide the temperature coefficients of the sensors, the estimations of $E$ o were plotted versus ( $t-25)$. The inclines of the straight lines acquired speak to the temperature coefficients of the cells and the sensor are $-0.34,0.73$ $\mathrm{mV} / \stackrel{\circ}{ } \mathrm{C}$, respectively. The little esteems uncover a thermal stability of the cell emf and the sensor potential inside the explored temperature go.

\section{Response to other Ions}

Response to some amino acids, essential inorganic cations and sugars which have been found in the pharmaceutical arrangements as excipients or added substances was explored. Selectivity coefficients were dictated by matched potential technique ${ }^{28}$ utilizing film, GC and GHB/KTPB sensors. The outcomes spoke in Fig. 3 demonstrate that the got selectivity coefficients are little and this shows a high selectivity of the readied sensors toward $\mathrm{CLPH}^{+}$. Inorganic cations don't meddle in light due to distinctions in ionic size, versatility and penetrability contrasted and $\mathrm{CLPH}^{+}$. The high selectivity over amino acids can be ascribed to the distinctions in extremity and lipophilic nature of their particles with respect to $\mathrm{CLPH}^{+}$.

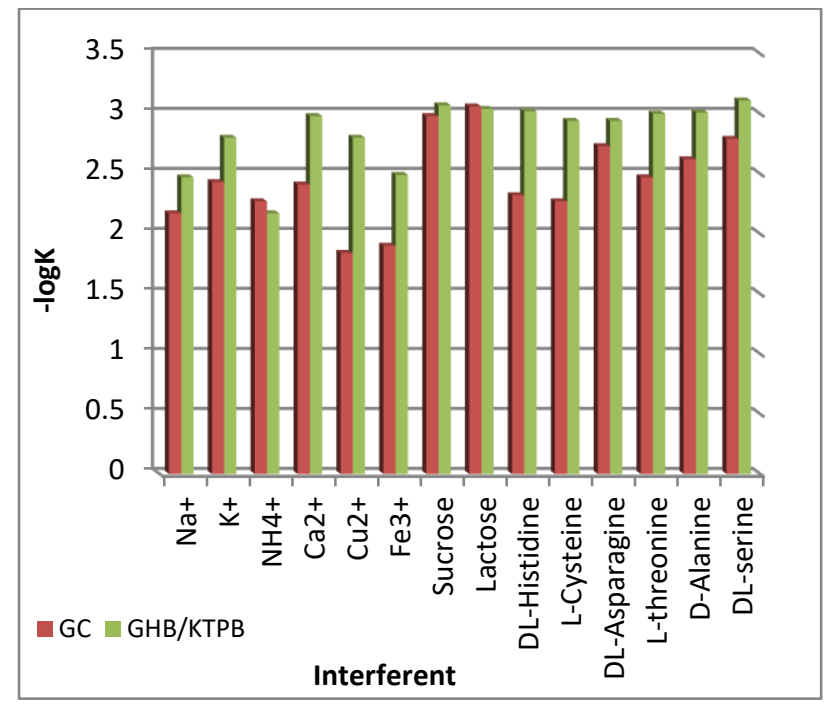

Figure 3: Selectivity coefficient $\left(-\log \mathrm{K}_{\mathrm{CLPH}^{+}, \mathrm{j}^{\mathrm{z}}}^{\mathrm{zot}}\right)$ of $\mathrm{GC}$ and GHB/KTPB sensors

\section{Effect of Different Graphite Grades on the Graphite} Coated Wire Sensor Response Characteristics

To study the effect of graphite grade on the response characteristics of graphite coated wire sensors, different pencil rods with graphite grades $\mathrm{HB}, 2 \mathrm{~B}, 4 \mathrm{~B}, \mathrm{H}$ and $4 \mathrm{H}$ were used as beds for construction of coated wire sensors with the composition of $2.0 \% \mathrm{CLPH}-\mathrm{TPB}+0.5 \% \mathrm{KTPB}+48.75 \%$ PVC+48.75\% TCP.

To consider the impact of graphite grade on the response attributes of graphite sensors, diverse pencil poles with graphite levels $\mathrm{HB}, 2 \mathrm{~B}, 4 \mathrm{~B}, \mathrm{H}$ and $4 \mathrm{H}$ were utilized as beds for development of solid contact sensor with the creation of $2.0 \% \mathrm{CLPH}-\mathrm{TPB}+0.5 \% \mathrm{KTPB}+48.75 \% \mathrm{PVC}+48.75 \% \mathrm{TCP}$. The sensors were set up as already talked about (section 2.5) at that point, they were molded in $1.0 \mathrm{mmol} / \mathrm{L} \mathrm{CLPH.Cl}$ for $15 \mathrm{~min}$, and every sensor was inspected in the focus range $1.0 \times 10^{-4}-10.0 \mathrm{mmol} / \mathrm{L} \mathrm{CLPH} . \mathrm{Cl}$. The outcomes demonstrate that the slope values are lower than the Nernstian esteem if there should be an occurrence of G2B $/$ KTPB (slope $=52.53 \pm 0.25 \mathrm{mV} /$ decade), G4B $/ \mathrm{KTPB}$ (slope $=51.10 \pm 0.30 \mathrm{mV} /$ decade) and GH/KTPB (slope $=$ $50.41 \pm 0.31 \mathrm{mV} /$ decade) and it increases in the event of GHB/KTPB (slope $=58.08 \pm 0.20 \mathrm{mV} /$ decade) and G4H/KTPB (slope $=59.39 \pm 0.23 \mathrm{mV} /$ decade). From the outcomes, it was discovered that G4H/KTPB has the most Nernastian slope $(59.39 \pm 0.23 \mathrm{mV} /$ decade) and LOD esteems (1.20 $\mu \mathrm{mol} / \mathrm{L})$. In addition, GHB/KTPB has slope of $58.08 \pm 0.20$ $\mathrm{mV} /$ decade and the low LOD esteem $0.49 \mu \mathrm{mol} / \mathrm{L}$.

From the obtained results, it was presumed that as the softness of the graphite rods increases from $2 B$ to $4 B$, the slope decreases and LOD values increase. As the hardness of the graphite rods increases from $\mathrm{H}$ to $4 \mathrm{H}$, the slope and LOD values increase. The mixture between $\mathrm{H}$ and $\mathrm{B}$ by ratio 1:1 gave the best outcomes.

\section{Analytical Applications}

\section{The Potentiometric Titration}

The potentiometric titration was connected to decide $\mathrm{CLPH} . \mathrm{Cl}$ in pure and pharmaceutical arrangements (Anafronil ${ }^{\circledR}$ tablets) utilizing the proposed sensors. The LOD esteem was computed by changing the volume of the taken CLPH.Cl by little additions till the sensor misfortunes its affectability, it was discovered that LOD and LOQ are 0.99 and $2.99 \mu \mathrm{mol} \mathrm{L}^{-1}$ utilizing GHB/KTPB sensor. For examine of the pure form, the got mean recoveries are in the range $103.24-99.50 \%$ with RSD\% 1.15-0.37\%, Table 3. For the examination of Anafronil ${ }^{\circledR}$ tablets $(25 \mathrm{mg} /$ tablet and $75 \mathrm{mg} /$ tablet), the got mean recoveries are in the range $99.66-98.97 \%$ with $\mathrm{RSD} \%$ of $0.90-0.52 \%$ uncovering that there is no interference from excipients or added substances utilized as a part of tablets, Table 3. 
Table 3: Determination of CLPH.Cl in pure solutions and pharmaceutical formulations applying potentiometric titrations using GHB/KTPB solid contact sensor.

\begin{tabular}{|c|c|c|}
\hline Taken, mg & Recovery\% $\pm S D$ & RSD* \\
\hline \multicolumn{3}{|c|}{ Pure solution } \\
\hline 1.2 & $103.24 \pm 0.39$ & 0.76 \\
\hline 1.8 & $101.30 \pm 0.44$ & 0.87 \\
\hline 3.9 & $100.62 \pm 0.23$ & 0.47 \\
\hline 10.6 & $102.99 \pm 0.19$ & 0.37 \\
\hline 25.0 & $99.50 \pm 0.57$ & 1.15 \\
\hline 35.5 & $99.50 \pm 0.28$ & 0.58 \\
\hline \multicolumn{3}{|c|}{ Anafronil ${ }^{\circ}$ tablet ( $25 \mathrm{mg} /$ tablet) } \\
\hline 1.5 & $99.66 \pm 0.45$ & 0.90 \\
\hline 2.5 & $98.97 \pm 0.34$ & 0.70 \\
\hline \multicolumn{3}{|c|}{ Anafronil ${ }^{\circ}$ tablet (75 mg/tablet) } \\
\hline 5.0 & $99.16 \pm 0.48$ & 0.97 \\
\hline 7.5 & $99.20 \pm 0.25$ & 0.52 \\
\hline
\end{tabular}

\section{The standard addition method}

The standard addition strategy was connected to measure $\mathrm{CLPH} . \mathrm{Cl}$ in pure pharmaceutical arrangements (Anafronil ${ }^{\circledR}$ tablets), spiked human serum and urine samples. The LOD and $L O Q$ are 30.0 and $99.9 \mathrm{nmol} / \mathrm{L}$ for GHB/KTPB sensors. The acquired mean recoveries are in the range 102.59$98.86 \%$ with RSD $\% 1.45-0.47 \%$. The procured results, Table 4 , demonstrate that the excipients or included substances used as a tablet component, human serum and urine tests have no impediment with $\mathrm{CLPH}^{+}$.

Table 4: Determination of CLPH.Cl in its pure solutions, pharmaceutical formulations and biological fluids applying the standard addition method using GHB/KTPB solid contact sensor.

\begin{tabular}{|c|c|c|}
\hline Taken & Recovery\% $\pm S D$ & RSD* \\
\hline \multicolumn{3}{|c|}{ Pure solution } \\
\hline $1.9 \mu \mathrm{g}$ & $98.86 \pm 0.47$ & 0.96 \\
\hline $2.0 \mu \mathrm{g}$ & $102.59 \pm 0.24$ & 0.47 \\
\hline $25.0 \mu \mathrm{g}$ & $101.83 \pm 0.31$ & 0.63 \\
\hline $3.0 \mathrm{mg}$ & $101.58 \pm 0.32$ & 0.64 \\
\hline \multicolumn{3}{|c|}{ Anafronil ${ }^{\circ}$ tablet ( $25 \mathrm{mg} /$ tablet) } \\
\hline $25.0 \mu \mathrm{g}$ & $101.60 \pm 0.74$ & 1.45 \\
\hline $2.3 \mathrm{mg}$ & $100.23 \pm 0.63$ & 1.26 \\
\hline \multicolumn{3}{|c|}{ Anafronil ${ }^{\circ}$ tablet ( $75 \mathrm{mg} /$ tablet) } \\
\hline $25.0 \mu \mathrm{g}$ & $99.16 \pm 0.48$ & 0.97 \\
\hline $2.3 \mathrm{mg}$ & $99.00 \pm 0.57$ & 1.16 \\
\hline \multicolumn{3}{|c|}{ Spiked human serum samples } \\
\hline
\end{tabular}

\begin{tabular}{|c|c|c|}
\hline $15.0 \mu \mathrm{g}$ & $102.41 \pm 0.44$ & 0.86 \\
\hline $1.8 \mathrm{mg}$ & $102.10 \pm 0.24$ & 0.48 \\
\hline \multicolumn{3}{|c|}{ Spiked human urine samples } \\
\hline $15.0 \mu \mathrm{g}$ & $102.25 \pm 0.54$ & 1.05 \\
\hline $1.8 \mathrm{mg}$ & $102.26 \pm 0.56$ & 1.07 \\
\hline
\end{tabular}

\section{Validation of the Methods}

\section{Ruggedness and Robustness of the Proposed Methods}

As per the USP meaning of ruggedness, the strategy is over and over performed under various test conditions to inspect the impacts of some "non-technique related" elements, for example, research laboratories, instruments, investigators, reagents, and time, without evolving the "system related" technique parameters [32]. To contemplate the ruggedness of the techniques, a correlation between the outcomes acquired by two investigators was performed. The RSD\% esteem acquired by two analysts in a similar lab is $0.66 \%$.

The impacts of little think changes in "methodology related" technique parameters, for example, operational, environmental and crest estimation/investigation parameters were investigated by robustness [32]. The later of the proposed methods was studied while the temperature of the solution was slightly changed. The recovery percentages were great under most conditions and don't demonstrate any huge change when the basic parameters were altered.

\section{Repeatability and Reproducibility}

The repeatability and reproducibility investigations of the readied sensors have been studied. For the repeatability think about, the calibration bends were completed four times for a similar sensor. For reproducibility, the sensor of a similar structure was prepared four times and the calibration bends were developed. It was discovered that RSD\% fluctuated from 0.35-0.84 and 0.55-0.91\%, respectively. Four repeated assurance at various fixation levels are completed utilizing the proposed sensor to test the exactness of the technique. The RSD\% esteems were observed to be under $2.0 \%$, demonstrating sensible repeatability and reproducibility of the proposed strategy.

\section{Statistical Treatment of the Obtained Data}

The outcomes were factually contrasted and those acquired by the pharmacopeial strategy [1] utilizing combined t-and F-tests, Table 5. At 95\% confidence level for four replicate estimations, the figured t-and F-values did not surpass the critical values, demonstrating that there is no significant distinction between the proposed technique and the official strategy with respect to precision and accuracy. 
Table 5: Statistical treatment of the obtained data for the determination of CLPH.Cl in comparison with pharmacopoeial method.

\begin{tabular}{|c|c|c|c|c|}
\hline & $X \pm S . E$ & RSD\%* & t-value & F-value \\
\hline Pharmacopoeial method & $101.59 \pm 0.72$ & 1.42 & & \\
\hline \multicolumn{5}{|c|}{ Potentiometric titration } \\
\hline \multicolumn{5}{|c|}{ GC sensor } \\
\hline Pure solution & $103.50 \pm 0.28$ & 0.55 & 0.59 & 0.15 \\
\hline Anafronil $^{\bullet}$ tablet (25 mg/tablet) & $98.92 \pm 0.41$ & 0.82 & 2.91 & 0.32 \\
\hline Anafronil $^{\circ}$ tablet (75 mg/tablet) & $99.52 \pm 0.31$ & 0.64 & 3.21 & 0.19 \\
\hline \multicolumn{5}{|c|}{ GHB/KTPB sensor } \\
\hline Pure solution & $101.30 \pm 0.44$ & 0.87 & 0.83 & 0.37 \\
\hline Anafronil ${ }^{\bullet}$ tablet ( $25 \mathrm{mg} /$ tablet) & $98.97 \pm 0.34$ & 0.70 & 0.23 & 3.24 \\
\hline Anafronil $^{\circ}$ tablet (75 mg/tablet) & $99.20 \pm 0.25$ & 0.52 & 3.09 & 0.12 \\
\hline \multicolumn{5}{|c|}{ Standard addition method } \\
\hline \multicolumn{5}{|l|}{ GC sensor } \\
\hline Pure solution & $100.65 \pm 0.53$ & 1.06 & 1.60 & 0.55 \\
\hline Anafronil $^{\circ}$ tablet (25 mg/tablet) & $101.31 \pm 0.43$ & 0.85 & 0.88 & 0.36 \\
\hline Anafronil ${ }^{\circ}$ tablet (75 mg/tablet) & $99.89 \pm 0.89$ & 1.78 & 2.28 & 1.53 \\
\hline Spiked serum samples & $103.56 \pm 0.51$ & 1.00 & 2.91 & 0.51 \\
\hline Spiked urine samples & $101.62 \pm 0.39$ & 0.77 & 0.36 & 0.29 \\
\hline \multicolumn{5}{|l|}{ GHB/KTPB sensor } \\
\hline Pure solution & $101.76 \pm 0.36$ & 0.72 & 0.27 & 0.25 \\
\hline Anafronil ${ }^{\circ}$ tablet ( $25 \mathrm{mg} /$ tablet) & $100.23 \pm 0.63$ & 1.26 & 1.34 & 0.77 \\
\hline Anafronil ${ }^{\circ}$ tablet $(75 \mathrm{mg} /$ tablet $)$ & $101.13 \pm 0.32$ & 0.65 & 1.34 & 0.20 \\
\hline Spiked serum samples & $102.10 \pm 0.24$ & 0.48 & 0.16 & 0.11 \\
\hline Spiked urine samples & $102.25 \pm 0.54$ & 1.07 & 0.34 & 0.56 \\
\hline t-tabu & $\begin{array}{l}\text { Recovery } \pm \text { stan } \\
3 \text { at } 99.0 \% \text { and } \\
\text { s } 9.82 \text { at } 95.0 \%\end{array}$ & $\begin{array}{l}\text { cor. } \\
\text { e of free } \\
\text { ence limit }\end{array}$ & & \\
\hline
\end{tabular}

\section{CONCLUSION}

The present work includes the arrangement of clomipramine hydrochloride solid contact sensors in light of the usage of CLPH-TPB as an electroactive issue. The impact of various graphite grades demonstrated that pencil of $\mathrm{HB}$ review gave the best outcomes; has slope of $58.08 \pm 0.20 \mathrm{mV} /$ decade and the low LOD value 0.49 $\mu \mathrm{mol} / \mathrm{L}$. These sensors were portrayed and improved by IUPAC recommendations. The selectivity thinks about uncovered that the readied sensors have high selectivity toward $\mathrm{CLPH}^{+}$over an extensive variety of different cations and essential molecules. These sensors were effectively connected for the assurance of $\mathrm{CLPH} . \mathrm{Cl}$ in pure, Anafronil ${ }^{\circ}$ tablets and spiked human serum and urine samples in the range $102.59-98.86 \%$ with $\mathrm{RSD} \%<1.5 \%$. The got comes about are in great concurrence with those got from the British pharmacopeial one. The outcomes demonstrate that the recommended sensors have a wide linearity, Nernstian slope, low LOD, LOQ esteems and long-life time. They are likewise repeatable and reproducible sensors with RSD under $2.0 \%$.

\section{REFERENCES}

1. British Pharmacopoeia Cambridge University Press, Cambridge 1, UK, 2014; pp 585-586.

2. Tatsumi M, Groshan K, Blakely RD, Richelson E, Pharmacological profile of antidepressants and related compounds at human monoamine transporters, Eur. J. Pharm, 1997; 340: 249-258.

3. Mohamed FA, Hussein SA, Mohamed HA, Ahmed SA, The use of Quercetin for spectrophotometric determination of some CNS acting drugs, Bull. Pharm. Sci, 2003; 26: 15-27.

4. Lakshmi AV, Spectrophotometric method for estimation of clomipramine in bulk and tablet dosage form, Int. J. Pharm. Sci. Res. 2013; 4: 1610-1613.

5. Marques KL, Santos JL, Lima JLF, Multicommutated flow system for the chemiluminometric determination of clomipramine in pharmaceutical preparations, Anal. Chim. Acta, 2004; 518: 31-36.

6. Ji Z, Yao X, Li J, Determination of clomipramine by flow-injection analysis with acidic potassium permanganate-formic acid chemiluminescence detection, Luminescence, 2011; 26: 741-746.

7. Rahman N, Afaq N, Optimization and validation of spectrofluorimetric method for the determination of clomipramine 
hydrochloride via ion-pair complexation with alizarin red S, Anal. Methods, 2010; 2: 513-518.

8. Kaur K, Malik AK, Study on the fluorescence quenching reaction of amitriptyline and clomipramine hydrochlorides with eosin $\mathrm{Y}$ and its analytical application, J. Fluoresc, 2013; 23: 533-542.

9. Nevado JJB, Llerena MJV, Salcedo AMC, Nuevo EA, Determination of fluoxetine, fluvoxamine, and clomipramine in pharmaceutical formulations by capillary gas chromatography, J. Chromatogr. Sci, 2000; 38: 200-206.

10. Kou HS, Chen CC, Huang YH, Ko YH, Wu HL, Wu SM, Method for simultaneous determination of eight cyclic antidepressants by cyclodextrin-modified capillary zone electrophoresis: Applications in pharmaceuticals, Anal. Chim. Acta, 2004; 525: 23-30.

11. Frahnert C, Rao ML, Grasmäder K, Analysis of eighteen antidepressants, four atypical antipsychotics and active metabolites in serum by liquid chromatography: a simple tool for therapeutic drug monitoring, J. Chromatogr. B, 2003; 794: 35-47.

12. Malfará WR, Bertucci $C$, Queiroz MEC, Carvalho SAD,. Bianchi MDLP, Cesarino EJ, Crippa JA, Queiroz RHC, Reliable HPLC method for therapeutic drug monitoring of frequently prescribed tricyclic and nontricyclic antidepressants, J. Pharm. Biomed. Anal, 2007; 44: 955-962.

13. Kristinsson J, A gas chromatographic method for the determination of antidepressant drugs in human serum, Acta Pharmacol. Toxicol, 1981; 49: 390-398.

14. Nevado JJB, Llerena MJV, Salcedo AMC, Nuevo EA, Determination of fluoxetine, fluvoxamine, and clomipramine in pharmaceutical formulations by capillary gas chromatography, J. Chromatogr. Sci, 2000; 38: 200-206.

15. Shinozuka $T$, Terada $M$, Tanaka $E$, Solid-phase extraction and analysis of 20 antidepressant drugs in human plasma by LC/MS with SSI method, Forensic Sci. Int, 2006; 162: 108-112.

16. Papoutsis I, Khraiwesh A, Nikolaou P, Pistos C, Spiliopoulou C, Athanaselis $\mathrm{S}$, A fully validated method for the simultaneous determination of 11 antidepressant drugs in whole blood by gas chromatography-mass spectrometry, J. Pharm. Biomed. Anal, 2012; 70: 557-562.

17. Soleymanpour A, Ghasemian M, Chemically modified carbon paste sensor for the potentiometric determination of carvedilol in pharmaceutical and biological media, Measurement, 2015; 59: 1420.

18. Abu Shawish HM, Abed Almonem KI, Saadeh M, Al-lham WS, Determination of haloperidol drug in ampoules and in urine samples using a potentiometric modified carbon paste electrode, Measurement, 2016; 78: 180-186.

19. Ardakani MM, Amini MK, Dehghan M, Kordi E, Sheikh-Mohseni MA, Preparation of $\mathrm{CU}$ (II) imprinted polymer electrode and its application for potentiometric and voltammetric determination of Cu (II), J. Iran. Chem. Soc, 2014; 11(1): 257-262.

20. Saber Tehrani M, Vardini MT, Abroomand Azar P, Husain SW, Molecularly imprinted polymer Based PVC-Membrane-Coated graphite electrode for the determination of metoprolol, J. Iran. Chem. Soc, 2010; 7(3): 759-769.

21. Tashkhourian J, Ghaderizadeh SM, Montazerozohori M, Nickelselective coated disk electrode based on carbon nanotube composite modified with a new Schiff base, Russ. J. Electrochem, 2015; 51(3): 209-217.

22. Buck RP, Linder $E$, Recommendations for nomenclature of ionselective electrodes (IUPAC Recommendations 1994), Pure Appl. Chem, 1994; 66: 2527-2536.

23. Issa YM, Mohamed SH, Elfeky S, Chemically modified carbon paste sensors for determination of clomipramine hydrochloride in pharmaceutical formulations, Int. J. Res. Pharm. Chem, 2014; 4: 723-734.

24. Faridbo F, Clomipramine determination by potentiometric PVC membrane and carbon paste sensors, Anal. Bioanal Electrochem. 2012; 4: 315-326.

25. Ortuño JA, Hernández J, Sánchez-Pedreño C, lon-selective electrode for the determination of some multidrug resistance reversers, Sensors Actuators B Chem, 2006; 119: 282-287.

26. Elqudaby HM, Frag EYZ, Mohamed GG, Mohamed MA, A Novel clomipramine and paroxetine-selective membrane sensors and their applications in pharmaceutical analysis, Anal. Bioanal. Electrochem, 2011; 3: 420-435.

27. Arvand $M$, Vejdani $M$, Moghimi $M$, Construction and performance characterization of an ion selective electrode for potentiometric determination of atenolol in pharmaceutical preparations, Desalination, 2008; 225: 176-184.

28. Umezawa $\mathrm{Y}$, Buhlmann $\mathrm{P}$, Umezawa $\mathrm{K}$, Tohda $\mathrm{K}$, Amemiya $\mathrm{S}$, Potentiometric Selectivity Coefficients of Ion-Selective Electrodes. Part I. Inorganic Cations (Technical Report), Pure Appl. Chem, 2000; 72: 1851-2082.

29. Baumann EW, Trace flouride determination with specific ion electrode, Anal. Chim. Acta, 1968; 42: 127-132.

30. Rounaghi G, Kakhki RMZ, Sadeghian H, A new cerium (III) ion selective electrode based on 2,9-dihydroxy-1,10-diphenoxy-4,7dithia decane, a novel synthetic ligand, Electrochim. Acta, 2011; 56: 9756-9761.

31. Issa YM, Hassouna MM, Abdel-Gawad FM, Hussein EM, Poly (Vinyl Chloride) Ion Selective Electrodes for Piribedil Determination, J. Pharm. Biomed. Anal, 2000; 23: 493-502.

32. Dejaegher B, Heyden YV, Ruggedness and robustness testing, J. Chromatogr. A, 2007; 1158: 138-157.

Source of Support: None declared.

Conflict of Interest: None declared.

For any question relates to this article, please reach us at: editor@globalresearchonline.net New manuscripts for publication can be submitted at: submit@globalresearchonline.net and submit_ijpsrr@rediffmail.com 